\title{
AVALIAÇÃO DE CUSTOS DE MANUTENÇÃO EM AUTOMÓVEIS-ESTUDO DE \\ CASO
}

Bruna Oliveira de Siqueira; UNINASSAU; bruubs@ hotmail.com.br

Thiago Henrique Marques de Albuquerque; Thiago.albuquerque82@gmail.com

\section{Resumo}

A manutenção surgiu no século dezesseis junto com a revolução industrial, mas foi na década de setenta que sua utilização foi de fato crucial. Desde então ela vem ganhando espaço, passando a ser vista com outros olhos e deixando de ser aquele mal indesejado, indo de

pequenos consertos a gerenciamento de problemas. É dividida em 5 principais tipos, sendo elas: preventiva, detectiva, corretiva, preditiva e engenharia da manutenção. Cada uma impactará o meio com suas especificações cabendo ao responsável escolher o melhor tipo observando o histórico da empresa e analisando quais resultados ele quer obter, evitando os custos da qualidade que ocorrem através de falhas, sejam elas retrabalhos, rejeições equivocadas e atrasos de produção, por exemplo, O propósito deste trabalho é a avaliação de alternativas para corrigir o mau funcionamento do eletro ventilador de carros populares por meio de análise de fluxo de ar e da solução proposta pela empresa, sugerindo soluções para o problema. Concentrando-se em duas áreas de estudo: a gestão da manutenção e os custos, sendo discorridas técnicas fundamentais para a manutenção e prevenção. Coletas foram feitas a partir de estudo de caso, dados do fabricante, artigos, revistas cientificas e publicações nas quais foram feitas comparações com dados do fabricante e elaborados gráficos e tabelas. Através disto foram observados que o eletro ventilador não consegue suprir pois seu motor não possui potência suficiente para gerar um fluxo de ar capaz de resfriar o radiador e o condensador, não cobrindo área suficiente para ser capaz de deixá-los na temperatura ideal de funcionamento. A solução proposta pela empresa foi de substituição da peça nos carros de modelo 2014/2015, e correção do defeito apenas nos modelos dos anos seguintes apresentando soluções não definitivas. Através de análises feitas usando arvore de falhas foram propostas três possíveis soluções sendo elas: Aumento da potência do motor do eletro ventilador, troca do modelo de hélice do ventilador e redirecionamento do fluxo de ar, na qual cada uma delas visa a melhora do problema de forma definitiva ou menos paliativa possível.

Palavras-Chaves: Árvore de falhas; custo da qualidade; gestão da manutenção. 


\section{Introdução}

A manutenção pode ser vista como uma estratégia para obtenção de resultados onde seu foco deve ser a soluções e gerenciamento de problemas. Para que uma empresa funcione o mais corretamente possível é preciso que existam clientes dispostos a comprar seus produtos e para isso é preciso oferecer serviços com qualidade (ACC, 2016). Custo de qualidade é tido pela ISO 8402:1986 como gastos decorrentes das atividades de prevenção de defeitos mais as perdas devidas a falhas internas e externas.

Onde os custos da qualidade será os custos de estar conforme mais os custos das não conformidades. Um passo de grande importância na gestão é evitar ao máximo que as falhas ocorram, Os custos com a prevenção da falha são os que mais trazem retorno pois evitam desperdícios. Devemos investir num controle de qualidade eficiente na identificação de falhas quando o produto ainda está na empresa, reconhecendo que deve-se gastar com testes e inspeções, com o propósito de identificar pontos fracos durante a produção (Qualiteam, 2016). Autores como Coral e Selig (1994) citam que a qualidade não é determinada pela empresa mais sim pelo consumidor onde a falta de qualidade gera prejuízos e esses custos advindos da falhas são custos da qualidade e servem para medir os programas de melhorias das empresas. É importante observar que na busca pelo ótimo a política de manutenção a ser adotada deve ser levada em consideração pois a manutenção escolhida impactará todo o meio através das suas especificações.

\section{Objetivos}

\subsection{Objetivo Geral}

Avaliar alternativas para corrigir o mau funcionamento de eletro ventilador de carros populares.

\subsection{Objetivos Específicos}

- Analisar a área de fluxo de ar e avaliar se esse fluxo supre o radiador e o condensador.

- Analisar a solução dada pela empresa para o mau funcionamento do eletro ventilador.

- Propor possíveis soluções para esse problema, comparando-as com a solução dada pela empresa. 


\section{Referencial teórico}

O surgimento da manutenção ocorreu com a revolução industrial e junto com ela a necessidade de reparação e substituição de peças em linhas de produção, autores como Carvalho(2012) acreditam que o surgimento da mesma divide-se em três fases, Porém há convergências, acreditando-se que existam quatro fases, que vai desde o século 16 até a década de 70. Durante essa faixa de tempo a manutenção foi ganhando espaço e subdividindose. Onde o entendimento da mesma iria abranger de reparação a práticas de gestão e finanças. Para que um maquinário funcione com plenitude é ideal que os mesmos sejam mantidos em condições de funcionamento adequadas, Todo equipamento ao decorrer de sua vida útil deverá passar por desgastes, limpezas, correções, inspeções entre outros. Rodrigues et al (2009 apud SLACK 2002) dizem que as empresas limitam a manutenção a forma que as mesmas tentam evitar as falhas. Pois sua visão sobre ela é apenas a reparação de itens, porém nos últimos anos a manutenção vem tendo um papel proativo que vai de inspeções à serviços de rotina. A manutenção pode ser dividida em cinco principais tipos, sendo eles:

Manutenção preventiva, corretiva: planejada e não planejada, detectiva, preditiva e engenharia da manutenção (PASCHOAL, et al, 2009).

\subsection{Manutenção preventiva}

A manutenção preventiva é a intervenção em equipamentos que ainda se encontram em condições operacionais obedecendo um plano pré-elaborado baseados em intervalos de tempos. A manutenção preventiva deve ser a principal em todas as empresas, sendo o coração das manutenções, Harilaus (2014, pág. 24) diz que uma vez definida deve ter caráter obrigatório se comparada as outras. O mesmo ainda diz que se considerarmos o custo total ela acaba saindo mais barata pelo fato do acompanhamento e domínio das paradas ocorrida nos equipamentos.

Menezes (et al 2015) dizem que a manutenção preventiva pode ser dividida em sistemática e por condição a primeira visa o serviço por tempo sem falha e a segunda a condição do serviço sem falha. Onde a primeira interfere diretamente em: manutenções corretivas planejadas e nas melhorias e modificações e a outra nas manutenções corretivas planejadas, nas sistemáticas e nas melhorias. É estruturada em ações sistemáticas que impedem e minimizam a degradação do equipamento (figura 1 ). 
Figura 1: estrutura da manutenção preventiva

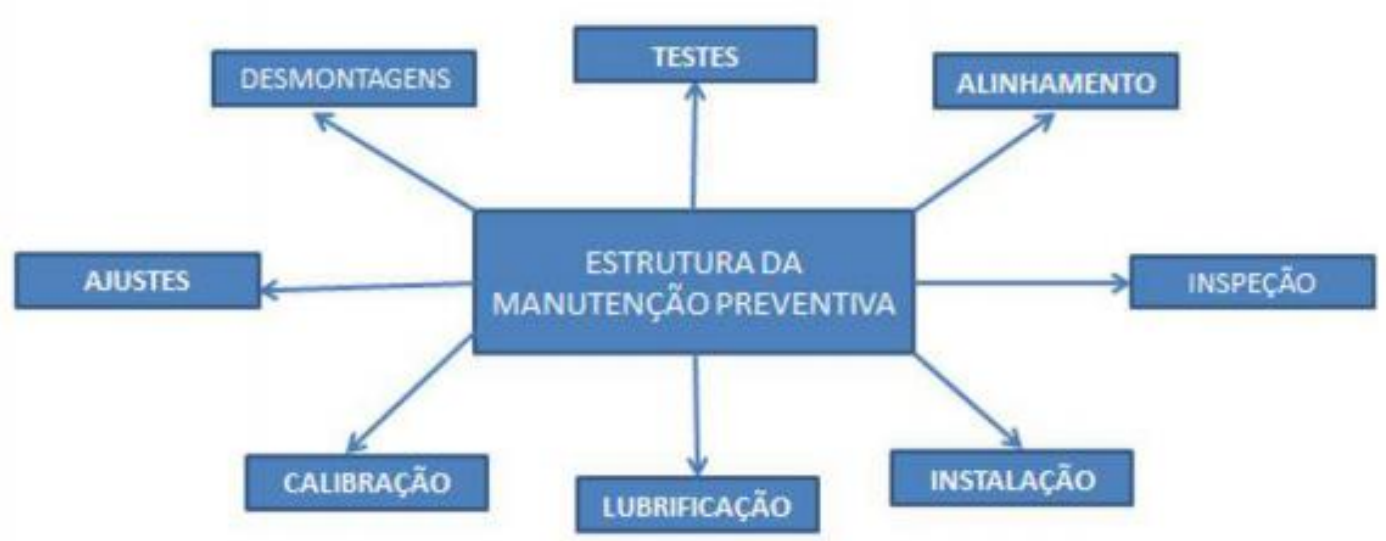

Fonte: Sullivan et al. (2018)

\subsection{Manutenção corretiva}

A manutenção corretiva é a reparação ou substituição com a intenção de restauração das condições iniciais da máquina, retirando as falhas existentes, há perdas de características da qualidade parcial ou total do produto, porém não ocorre perda total no resultado. Borges(2016); Gomes(2016) acreditam que este tipo de manutenção pode ser dividida em não planejada e planejada. A não planejada normalmente é de necessidade imediata pois a quebra ocorre de forma inesperada, já a programada serve como uma correção do desempenho abaixo do esperado, normalmente decidida pelo gestor do ambiente. A figura 2 mostra a comparação de ciclo de vida e custos de intervenções preventiva x corretiva, Onde a perda da qualidade altera diretamente no tipo de manutenção a ser utilizada. Podemos perceber também que a qualidade exigida muda com o tipo de manutenção a ser exercida no qual a corretiva exige um salto de qualidade bem maior que a preventiva e isso irá impactar no ciclo de vida do equipamento. 
Figura 2: Preventiva x corretiva

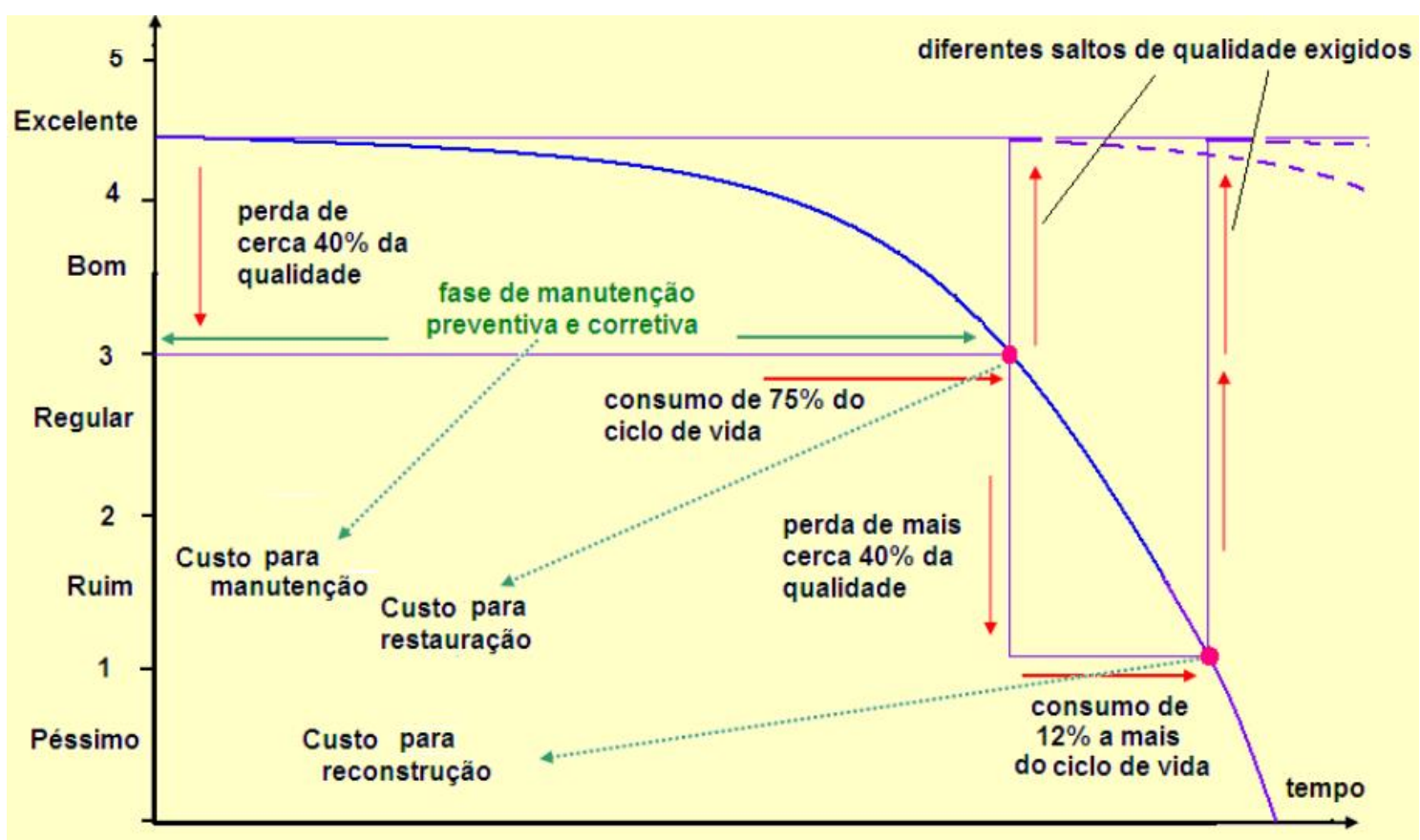

Fonte: Prof. José Tadeu Balbo (2017) Adaptado

\subsection{Manutenção detectiva}

A Manutenção detectiva é relativamente nova no Brasil, Rodrigues et al (2009) discorrem que o objetivo desta manutenção é achar falhas ocultas para o aumento da confiabilidade do equipamento sendo um tipo de manutenção especifica para sistemas automatizados e controlada por sistemas de controle e circuitos, Este tipo de manutenção é dividida por tipos de analises, onde algumas estão listadas no quadro 1:

Quadro 1: Tipos de analises

\begin{tabular}{|l|l|l|}
\hline Tipos de análise & Descrição & Fonte \\
\hline Emissão acústica & $\begin{array}{lr}\text { Detecta descontinuidades que } \\
\text { soltam energia de }\end{array}$ & \\
deformação quando a & IB-NDT \\
estrutura sofre tensão, & \\
varrendo áreas que outros & \\
métodos não varreriam, ideal & \\
\hline
\end{tabular}




\begin{tabular}{|l|l|l|}
\hline & $\begin{array}{l}\text { para estruturas de grande } \\
\text { porte. }\end{array}$ & $\begin{array}{l}\text { Usa-se os sentidos humanos } \\
\text { para observar variações no } \\
\text { equipamento, ruídos, cheiros } \\
\text { estranhos entre outros. }\end{array}$ \\
\hline Inspeção sensorial & LUBES- em foco. \\
\hline Índice de neutralização & $\begin{array}{l}\text { A NBR 14248(1999) diz que } \\
\text { este tipo de análise detecta a } \\
\text { presença de contaminantes } \\
\text { ácidos. }\end{array}$ & ABNT \\
\hline
\end{tabular}

\subsection{Manutenção preditiva}

É Conhecida também como uma manutenção com base no estado do equipamento, ela atua com base em parâmetros de condição ou desempenho e em intervalos definidos (MOURA ET AL 2008).

Harilaus G. (pág. 25) diz que a manutenção preditiva é um meio de inspecionar os equipamentos. Na figura 3 o gráfico exemplifica os tipos de manutenção utilizada através da condição do equipamento, dividida em 3 espaços de tempos. Poderemos notar que da faixa de tempo 1 e 2 o melhor tipo de manutenção para utilizar será a Preditiva, já para os intervalos 2 e 3 os melhores métodos preventivos vem da manutenção detectiva. 
Figura 3: Manutenção preditiva x detectiva

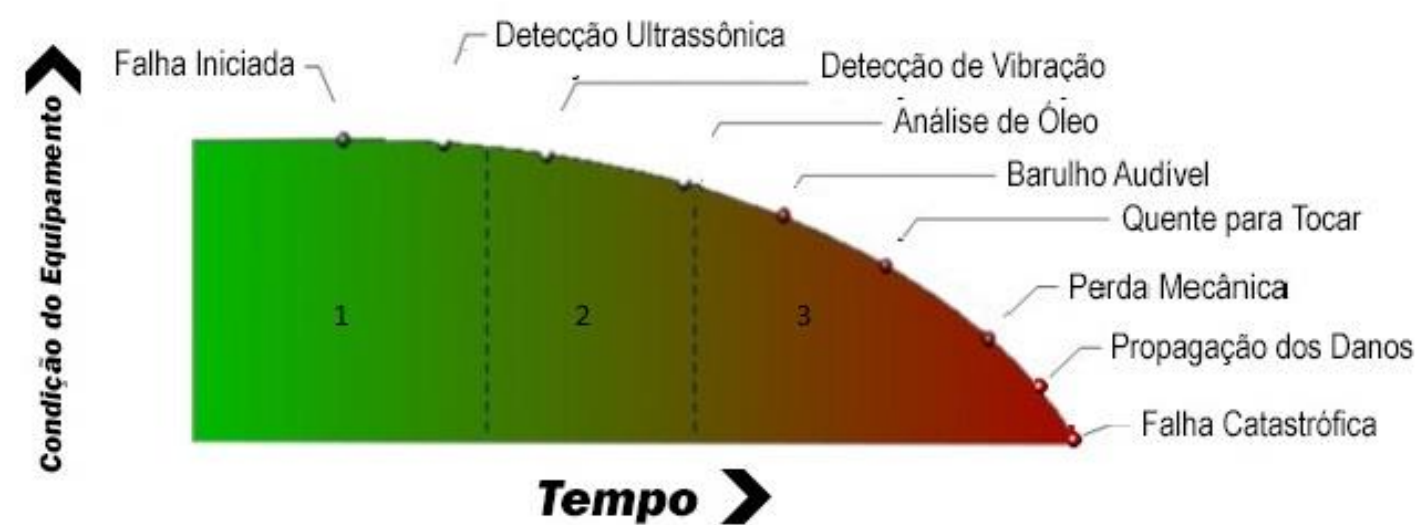

Fonte: VZanellato. (2019), Adaptado

\subsection{Engenharia da manutenção}

A engenharia da manutenção: É um pilar fundamental dentro de qualquer empresa, ela busca o constante aperfeiçoamento do setor da manutenção e sua área de atuação vai de projetar melhorias até a modificação de sistemas. Sendo seu objetivo principal gerar/aumentar a confiabilidade, disponibilidade e mantenabilidade. (TELES; 2016).

Para garantir a confiabilidade a engenharia da manutenção se válida de algumas formas, como: FMEA, FTA e DBC

- FMEA (análise do modo e efeito das falhas): Pode servir como base para uma manutenção centrada na confiabilidade. Sanson (2011); Coelho (2011) dizem que o objetivo do FMEA se divide em: avaliar falhas potenciais, identificar ações que reduzam a ocorrência dessa falha e documentar o estudo criando um referencial teórico para momentos futuros.

A aplicação FMEA em um projeto deve iniciar antes ou durante a criação do projeto, ser atualizado sempre que houver mudanças e está completo antes da construção do produto.

- FTA (Árvore de falhas): serve para caracterizar as falhas individuais das falhas durante o processo, sendo um procedimento indutivo onde mostra todos os resultados providos de um problema e quais impactos que possam ocorrer. O IME (2008) disse em um de seus cursos que os benefícios deste tipo de conceito é o domínio das características do equipamento, reconhecimento da sequência de falhas e melhor comunicação entre os integrantes da equipe. Podendo ser usadas tanto em falhas 
básicas quanto para calcular a próxima ocorrência de tal falha, Além de fácil interpretação.

A figura 4 mostra uma estrutura base usada em uma árvore de falhas.

Figura 4: Estrutura básica

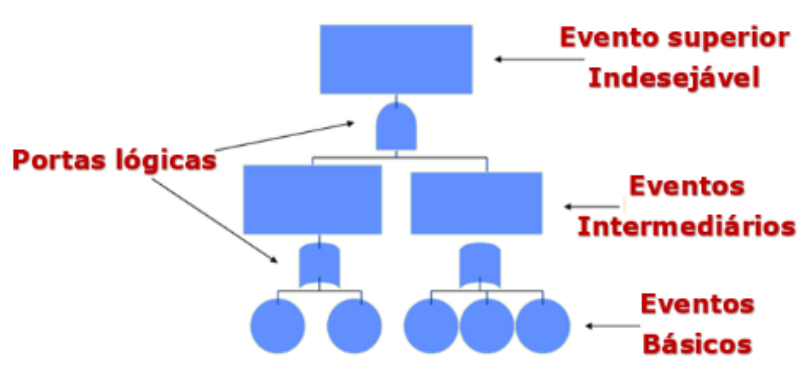

Fonte: Manutenção em Foco, analises e treinamento (2017)

- DBC (Diagramas de blocos de confiabilidade): É inversamente logico a árvore de falhas, sendo usado para falhas ou modos de falha de algum componente, mais fácil que o modo RAM pois os parâmetros inseridos é obtido através de simulações. Os diagramas de blocos podem ser: em cascata (figura 5), paralelos (figura 6) e em realimentação (figura 7).

Figura 5: Diagrama em cascata

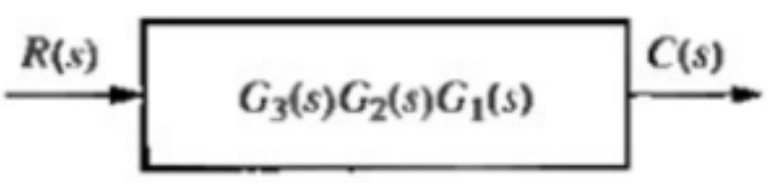

Fonte: Cristiano Quevedo Andrea (2012)

Onde R(s): é a entrada, C(s): a saída e (G3(s)G2(s)G1(s)): a função de transferência do bloco. A saída será o resultado do produto entre a entrada e o sistema. 
Figura 6: Diagrama em paralelo

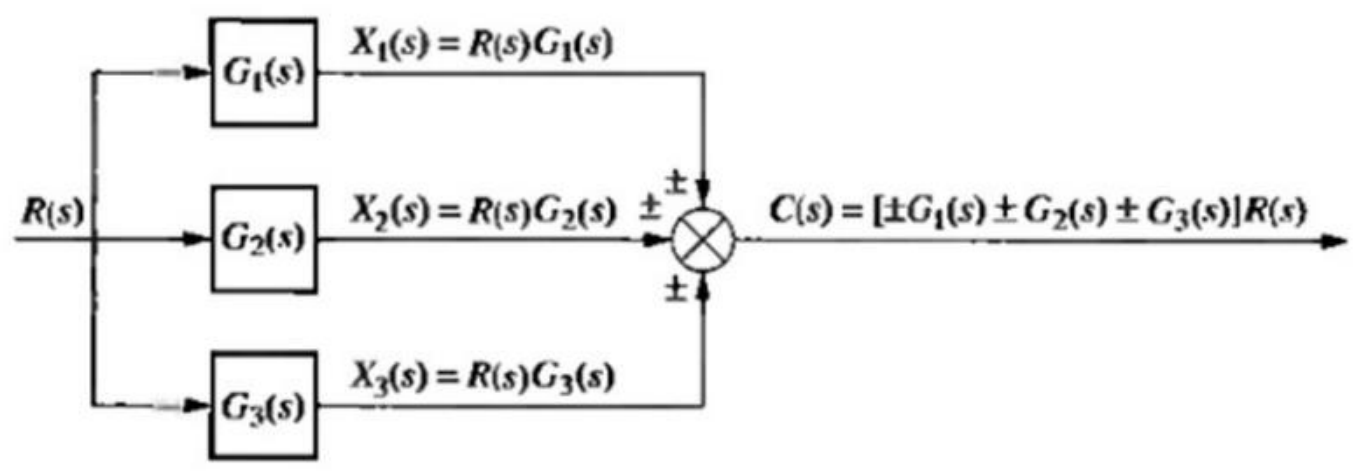

Fonte: Cristiano Quevedo Andrea (2012)

A função de transferência será a soma da função desses blocos.

Figura 7: Diagrama em realimentação

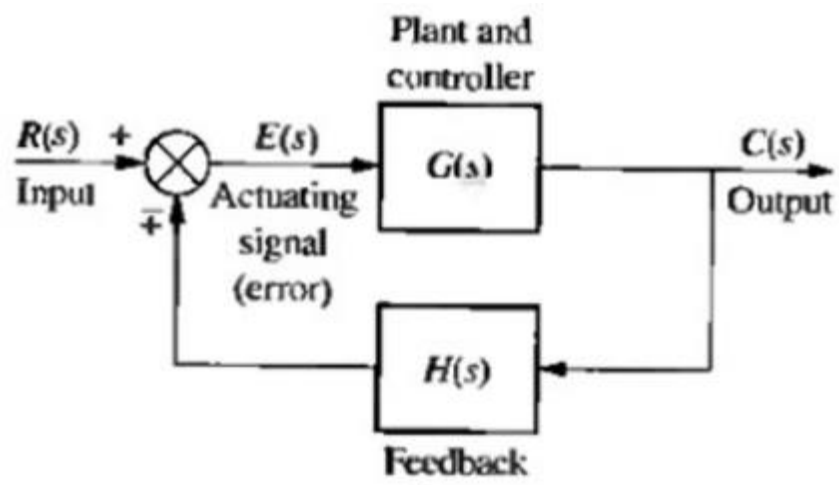

Fonte: Cristiano Quevedo Andrea (2012)

Esse tipo possui uma retroação negativa e outra positiva, Onde uma é função de transferência aberta e a outra fechada. Quando se consegue manter a confiabilidade nota-se um aumento na disponibilidade, que é usada como avaliação de desempenho para os equipamentos

\section{Metodologia}

O presente trabalho busca explorar duas áreas da engenharia mecânica: a gestão da manutenção e os custos relacionados sendo discorridos técnicas fundamentais para o bom funcionamento do maquinário e para o cuidado, manutenção e prevenção objetivando a 
diminuição de paradas e de quebras através dos diferentes tipos de manutenção e suas particularidades, podendo ou não serem usadas individualmente ou em conjunto. As coletas das informações foram feitas a partir da observação do caso e dos dados do fabricante, além de livros, artigos e publicações na área.

\section{Resultados e discussão}

O proprietário do veículo relatou que a um ano e meio vem tendo problemas com a refrigeração do seu carro de modelo Nissan sentra 20 SL CVT -2014/2015- prata. Foi feita uma análise do carro e constatado um mau funcionamento do eletro ventilador. Observados as especificações do carro e avaliado o problema, o próximo passo será a análise de fluxo de ar.

\subsection{Analise de fluxo de ar}

A figura 8 mostra um circuito feito pelo liquido de arrefecimento e também a forma de resfriamento sem o uso da ventoinha onde as setas indicam a entrada principal de fonte de massa de ar para o resfriamento.

Figura 8: sistema de arrefecimento sem ventoinha

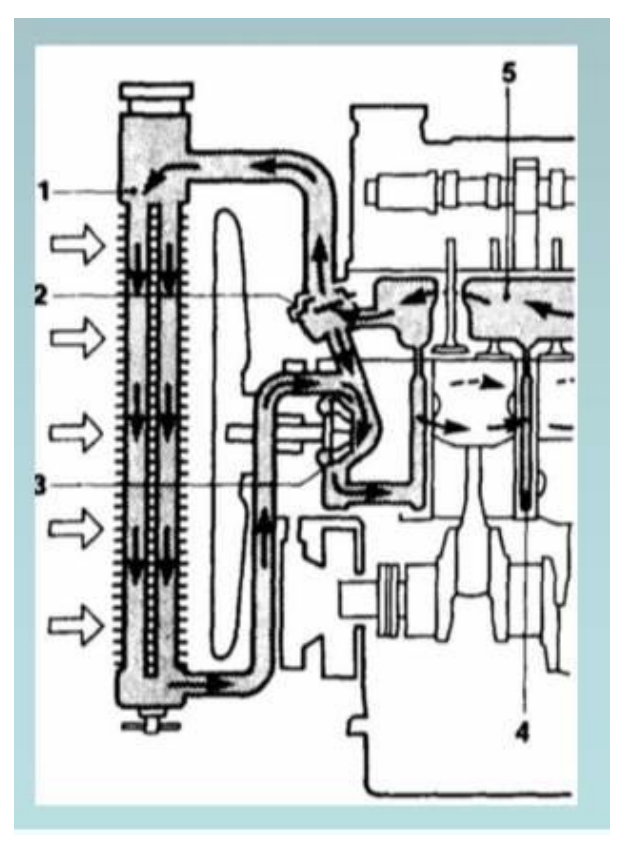

Fonte: Barros, J.; Beatas J. (2016)

Também podemos perceber pela figura 8 que as setas estão indicando que o vento vem de fora para dentro em direção do radiador. 
Fluxo ambiente: ambiente $\rightarrow$ radiador

Quando o vento não vem de fora em direção ao radiador o processo ocorre o inverso sendo do ventilador para fora, forçando o ar. Ele irá forçar o ar a correr no sentido contrário fazendo a troca de calor, como podemos ver na figura 9.

Figura 9: sistema de arrefecimento com ventoinha

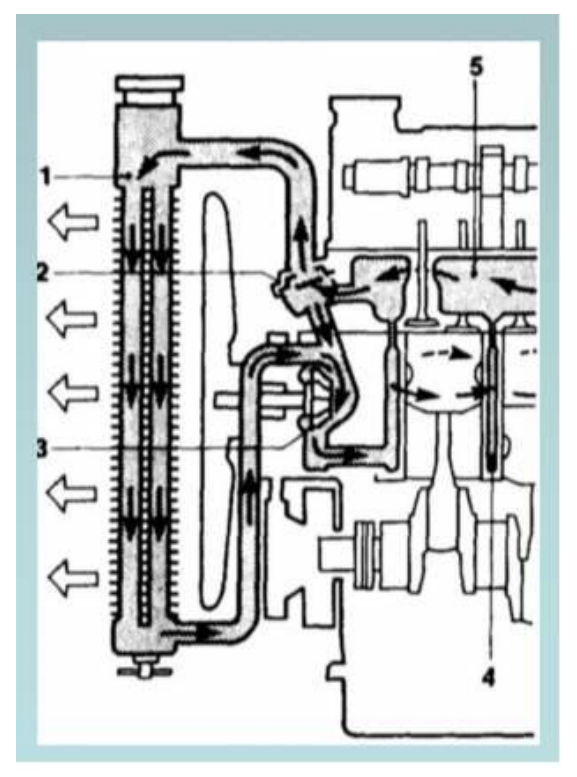

Fonte: Borges J.; Beatas J. (2016) Adaptado

Fluxo ventoinha: Ventoinha $\rightarrow$ radiador $\rightarrow$ ambiente.

A transferência de calor afeta diretamente a eficiência e o desempenho dos motores, o eletro ventilador atua como compensação de resfriamento, quando a ventilação admitida pela entrada de ar frontal não é suficiente para a troca de calor, ele é acionado e seu trabalho é forçar o ar contra o radiador e condensador afim de resfriar por meio de troca de calor.

\subsection{O fluxo supre ou não supre?}

O sistema de arrefecimento deve manter o carro na temperatura ideal de funcionamento sendo geralmente a $90^{\circ}$ Celsius, pois o motor esquenta muito com as explosões da queima do combustível. Esse sistema deve manter o propulsor frio para que as peças não derretam, mas não a ponto que o carro não funcione direito (Ferreira, 2017).

A MTE (2017) descreve o funcionamento básico de um sistema de arrefecimento funciona da seguinte maneira: $\mathrm{O}$ bom funcionamento do radiador, ventoinha, bomba d'agua, mangueiras e reservatório além da válvula termostática, interruptor térmico e sensor de temperatura são 
extremamente fundamentais para o sistema, Quando o veículo está em movimento a válvula termostática é a peça que faz a divisão entre o liquido motor/radiador sua função é a manutenção da temperatura para um bom funcionamento do motor.

Visto o funcionamento básico do sistemas podemos inferir que o fluxo não está sendo suficiente pois o motor não tem potência suficiente para gerar um fluxo de ar capaz de resfriar o radiador. O motor do eletro ventilador não possui potência suficiente para gerar o fluxo de ar e as partes de ventilação não cobrem áreas suficientes do radiador e condensador para esfriar o veículo em uma temperatura ideal de funcionamento.

\subsection{Solução dada pela empresa}

A solução proposta pela empresa foi a substituição da peça por uma nova do mesmo modelo. Sendo cobrado pela mesma um custo de $\mathrm{R} \$ 3.900$ para a troca, havendo alteração no preço cobrado se o carro não estiver dentro da garantia, pois será incluso o diagnóstico feito pela licenciada da empresa. Outra solução foi a troca do modelo de apenas uma ventoinha para o modelo de duas ventoinhas porém só foi aplicada para os modelos de 2016 em diante, Onde os mesmos já viriam de fábrica com o novo modelo de ventoinha. A troca da peça por outra do mesmo tipo não será eficaz, a resposta encontrada pela empresa encara a situação como uma peça de desgaste simples e um problema comum mas não é, pois a ineficiência do eletro ventilador vem através da insuficiência em suprir a temperatura, então a troca da peça desgastada por uma nova será apenas um paliativo. Esse modelo foi trazido ao Brasil sem reajuste algum, o qual acarreta em episódios parecidos com o caso de estudo deste trabalho, as condições climáticas dos dois países são diferentes, um motor de origem estrangeira foi desenvolvido para trabalhar em determinadas condições quando há compra deste modelo para um local onde as condições são diferentes deverá ocorrer mudanças nos projetos do carro.

O modelo sentra traz um design fechado se comparado a outros carros onde há apenas uma passagem de ar para resfriamento do motor que se encontra na frente do carro, indicado por setas na figura 10 . 
Figura 10: entrada de ar

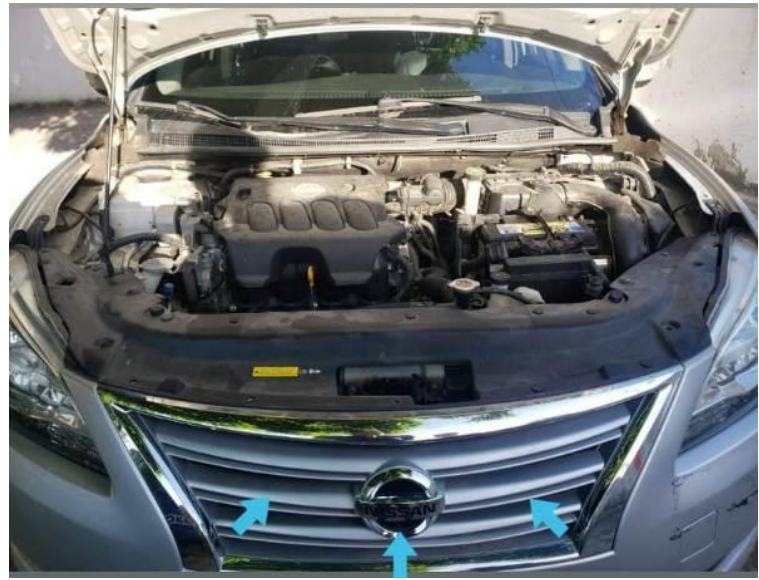

Fonte: Autor (2019)

A soma destes fatores faz com que haja uma sobrecarga de temperatura no qual a ventoinha não é capaz de resfriar com eficiência causando alteração na parte de arrefecimento do carro. Apesar de ser um problema recorrente nos modelos sentra 2014/2015 a empresa não fez o RECALL do modelo, negligenciando os clientes de um erro cometido por ela e cobrando o reparo dos mesmos. Ofertando soluções paliativas sem informar o cliente de que o problema voltará com determinado tempo de uso, já que a solução de fato só foi implantada a partir dos modelos de 2016 em diante. Que foi a substituição da ventoinha única (figura 11) pelo modelo de ventoinha dupla (figura 12).

Figura 11: ventoinha sentra 2014/2015

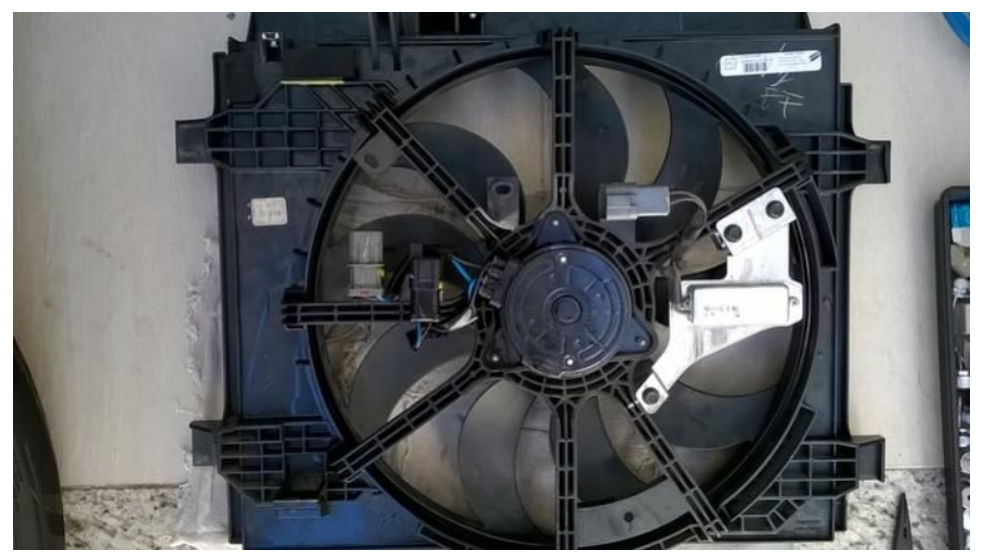

Fonte: Nissan Clube (2016) 
Figura 12: Modelo ventoinha dupla

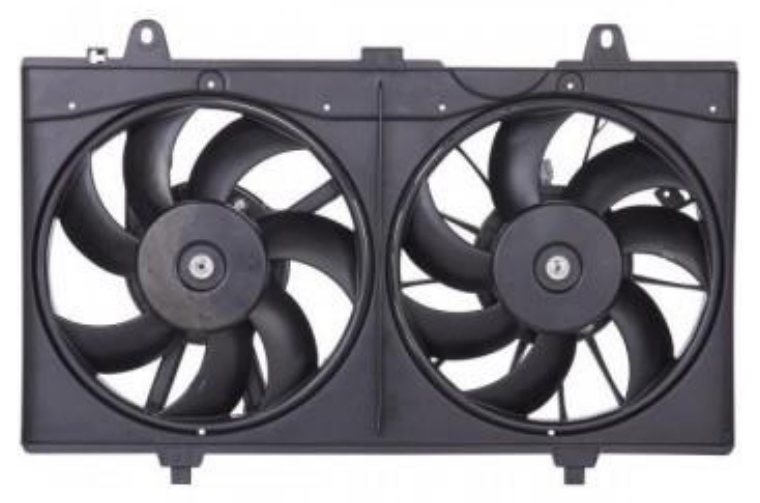

Fonte: Rt car import. (SEM ANO)

\subsection{Possíveis soluções}

Após análise foram propostos ao proprietário 3 possíveis soluções. Aumento da potência do motor do eletro ventilador, troca do modelo de hélice do ventilador e redirecionamento do fluxo de ar.

Será possível aumentar a potência do motor por meio de recondicionamento de bobina e/ou troca de um eletro ventilador de maior potência. $\mathrm{O}$ método de recondicionamento incluí mas não se resume em: revisar rolamentos, alinhar e centralizar o induzido.

A hélice é responsável por direcionar o ar, sua troca será eficaz pois ao colocar uma com maior área de contato o resfriamento no condensador e no radiador será maior e mais rápido. Já o redirecionamento ocorrerá com o reposicionamento das aletas da grade frontal para atingir diretamente a superfície a ser resfriada de forma direta, Isso servirá para aliviar o trabalho do motor do eletro ventilador melhorando o esfriamento natural de forma eficiente direcionando o ar ambiente a atingir toda a superfície a ser resfriada. Uma grande ferramenta usada na formulação das soluções foi a árvore de falhas, onde foi possível uma visualização ampla e melhora do entendimento da situação. 
Sua aplicação no presente trabalho foi feita de uma estrutura base e de acordo com as respostas das medidas tomadas foi se adicionando mais possibilidades, de modo que ao final o consumidor possa optar pela forma mais condizente dentro das suas possibilidades, apesar das três soluções propostas a analise não se finda, visto que a mesma irá depender da resposta apresentada pelo automóvel a solução escolhida.

Cada solução foi proposta de forma que o consumidor tenha o mínimo de gastos paliativos, pois todas as três foram pensadas para que o carro trabalhe de maneira definitiva preferencialmente ou que estenda ao máximo a eficiência e o tempo de vida de cada peça sem que haja o desgaste demasiado. A figura 13 mostra a árvore de falhas montada durante o processo de tomadas de decisões. 
Figura 13: Árvore de falhas 




Fonte: Autor (2019) 


\section{Conclusões}

Para um bom funcionamento do sistema de arrefecimento um sistema com ventoinha deve funcionar de maneira que o fluxo de ar passe por ela, pelo radiador e logo após passe para o ambiente, essa transferência de calor quando não feita de maneira eficiente acaba por afetar o desempenho dos motores, $O$ papel do eletro ventilador é apenas ser um meio de compensação de resfriamento quando a troca térmica do ambiente não é suficiente.

Devido ao modelo Nissan sentra 2014/2015 ser fechado se comparado aos outros veículos o eletro ventilador não consegue entregar potência suficiente além das partes de ventilação do modelo não cobrirem totalmente as áreas do condensador e radiador. A empresa se mostra despretensiosa em ajudar o consumidor deste modelo de veículo, pois trata o problema como um simples desgaste de peça porém o problema em si vai mais além, visto que o modelo não é de origem brasileira e faz com que o mesmo precise de alterações para que funcione perfeitamente com as peculiaridades climáticas do Brasil sem grandes impactos. Apesar de receber reclamações dos usuários do modelo sobre o mesmo problema, a empresa não ofereceu o recall para seus consumidores e ainda cobrou peça troca da peça, não explicando ao consumidor que essa troca seria apenas um paliativo e que o problema retornaria, fazendo com que seus consumidores paguem por um erro que ela cometeu.

Como possíveis soluções que diminuiriam o prejuízo do consumidor foram indicadas três propostas onde a primeira seria o aumento de potência do motor do eletro ventilador através do recondicionamento da bobina e/ou troca por um de maior potência, A segunda seria a troca do modelo de hélice no qual seria uma troca interessante porque o modelo utilizado atualmente age apenas na parte central do veículo e está troca aumentaria a área de contato de resfriamento. A terceira é o redirecionamento do ar onde o reposicionamento das aletas frontal aliviaria o motor do eletro ventilador o fazendo trabalhar menos e melhoria o esfriamento natural eficientemente. 


\section{Referências bibliográficas}

ABNT- ASSOCIAÇÃO BRASILEIRA DE NORMAS TECNICAS. NBR 14248. Acesso: 03/19

ACC- ENGENHARIA DE MEDIÇÃO. Entendendo os custos da qualidade e seus impactos econômicos. Disponível em:<http://www.accpr.com.br/entendendo-os-custos-da-qualidade-e-seus-impactos-economicos/> Acesso: 02/19

ANDREA, C.Q.; AMARAL, C. Diagrama de blocos. Disponível em: <file://3_2\%20-

\%20Diagrama\%20de\%20Blocos.pdf/> Acesso:04/19

AUTO ESPORTE. Autoajuda: sistema de arrefecimento. Disponível em: $<$ https://revistaautoesporte.globo.com/Servico/autoajuda/noticia/2015/05/autoajuda-sistema-dearrefecimento.html/> Acesso: 04/19

BALBO, J.T. gerencia de manutenção princípios básicos. Disponível em: $<$ https://edisciplinas.usp.br/pluginfile.php/2323482/mod_resource/content/1/Principios\%20de\%20gereencia\%20 de\%20manutenc\%CC\%A7a\%CC\%83o.pdf/> Acesso:03/19

BARROS, J.E.M.; BAETA, J.G.C. estudo da transferência de calor em motores. Disponível em:< file://TransferenciaCalor_Teoria.pdf/>, acesso: 04/19

BLOG QUALITEAM. Como identificar os custos da qualidade na sua empresa? Disponível em: <http://blog.qualidadesimples.com.br/2016/10/24/como-identificar-os-custos-da-qualidade-na-sua-empresa/ /> Acesso: 03/19

BORGES, J.R.; GOMES, M.C. manutenção preditiva em motores de combustão interna por analise do óleo lubrificante. Disponível em: <http://bd.centro.iff.edu.br> Acesso: 02/19

CARVALHO, F. A evolução da manutenção e quais os tipos de manutenção existentes nas empresas. Disponível em: <http://sistemasdegestaointegrada.blogspot.com/2012/08/a-evolucao-da-manutencao-e-quaisos.html/> Acesso: 03/19

CORAL, E.; SELIG, P.M. custos de qualidade: sua definição e aplicação. Disponível em: <https://anaiscbc.emnuvens.com.br/anais/article/viewFile/3520/3520/> Acesso: 04/19

CYRINO, L. Fta (fault tree analysis) - parte i. Disponível em: <https://www.manutencaoemfoco.com.br/ftafault-tree-analysis-parte-i//> Acesso:04/19

GM. Sistema de arrefecimento. Disponível em: <https://www.oficinabrasil.com.br/hotsites/gm/set_2011.pdf /> Acesso: 04/19

HARILAUS. G.X. Gerenciamento a manutenção produtiva. Pg-24 BELO HORIZONTE 1998.

IB-NDT. Emissão acústica. Disponível em: <http://ibndt.com/ver_servicos.asp?codigo=13\&secao=1/>Acesso: $02 / 19$

IME- INSTITUTO MILITAR DE ENGENHARIA. Árvore de falhas. Disponível em: <http://www.sucena.eng.br/IME/Mod6_ArvoreFalhas2008.pdf/> Acesso: 03/19

ISO 8402-1986 - Gestão da qualidade e garantia da qualidade. < Https://www.abntcatalogo.com.br/norma.aspx?ID=58542> Acesso em: 04/2019

LUBES EM FOCO. Os quatro sentido monitorando equipamentos industriais. Disponível em: <http://www.lubes.com.br/Newsletter/News/2017/170430/pdf/170430-04.pdf/> Acesso: 02/19

MENEZES, G.C.; SANTOS M.M.N. \& CHAVES, G.L.D. o pilar manutenção planejada da manutenção produtiva total (tpm): aplicação da manutenção centrada em confiabilidade (rcm). Disponível em: <https://revistas.utfpr.edu.br/revistagi/article/view/3004/> Acesso: 02/19

MOURA, F.L.; SANTOS, G.R.M. \& SANTOS, M.J.M. proposta de metodologia de trabalho com técnicas de manutenção preditiva e preventiva. Disponível em: <http://www.abraman.org.br/Arquivos/170/170.pdf/> Acesso: 03/19

MTE THOMSON. Sistema de arrefecimento.201(3m12s). Disponível em: <https://www.youtube.com/watch?v=xV9AfgtCE1U>. Acesso em: 03/19

NISSAN CLUBE. Eletro ventilador (ventoinha, radiador). Disponível em: <http://www.nissanclube.net.br/t1435-eletro-ventilador-ventoinha-radiador-novo-sentra-b17-falta-de-recall/> Acesso: 05/19 
PASCHOAL, DÉBORA RODRIGUES DE SOUZA ET AL. disponibilidade e confiabilidade: aplicação da gestão da manutenção na busca de maior competitividade. Disponível em:

<http://www.fsma.edu.br/EP/Artigos/REV_ENG_3_artigo_3.pdf.> Acesso em: 02/19

RODRIGUES, D.S.P. et al. Disponibilidade e confiabilidade: aplicação da gestão da manutenção na busca da maior competitividade. Disponível em:

<http://www.salesiana.edu.br/EP/Artigos/REV_ENG_3_artigo_3.pdf/>Acesso: 03/19

RT CAR IMPORT. Ventoinha radiador completo Nissan sentra 2.0. Disponível em:

<https://www.rtcarimport.com.br/ventoinha-radiador-completo-nissan-sentra-p2755/> Acesso: 04/19

SANSON, F.F.; COELHO, C.H. Aplicação de fmeca para definição de estratégias de manutenção em um sistema de controle e instrumentação de turbo geradores. < 2594-10659-1-pb.pdf> Acesso em: 03/19

SANTOS, R.S. manutenção preventiva e corretiva estudo de caso: maquinas de envase de manteiga em pote em uma fábrica de laticínio. Disponível em: 〈http://repositorio.ufu.br/handle/123456789/23068/> Acesso: 05/19

SSPREDITIVA. Manutenção proativa. Disponível em: <http://sspreditiva.com.br//> Acesso: 02/19

TELES, J. Engenharia da manutenção: foco em confiabilidade, disponibilidade e mantenabilidade. Disponível em: <https://engeteles.com.br/engenharia-de-manutencao/ /> Acesso: 05/19 